\title{
EXPERIENCE OF CZECH CHILDREN WITH ALCOHOL CONSUMPTION IN RELATION TO SELECTED FAMILY INDICATORS
}

\author{
Lenka Hodačová ${ }^{1}$, Jindra Šmejkalová2, Eva Čermáková3, Michal Kalman ${ }^{4}$ \\ ${ }^{1}$ Department of Social Medicine, Faculty of Medicine in Hradec Kralove, Charles University, Hradec Kralove, Czech Republic \\ ${ }^{2}$ Department of Hygiene and Preventive Medicine, Faculty of Medicine in Hradec Kralove, Charles University, Hradec Kralove, Czech Republic \\ ${ }^{3}$ Computer Technology Centre, Faculty of Medicine in Hradec Kralove, Charles University, Hradec Kralove, Czech Republic \\ ${ }^{4}$ Department of Recreology, Faculty of Physical Culture, Palacký University Olomouc, Olomouc, Czech Republic
}

\section{SUMMARY}

Objective: The aim of this study is to monitor and analyze the influence of chosen family indicators related to alcohol consumption and experience of drunkenness in a representative sample of Czech children.

Methods: Data for our work were obtained from the Health Behaviour in School Aged Children (HBSC) study - a World Health Organization (WHO) cross national study. The sample consisted of 4,293 children aged 11, 13 and 15 years. Data collection was conducted in June 2010 in 88 randomly selected schools in the Czech Republic using standardized questionnaires. Statistical analysis was performed in the program NCSS 9 , methods of descriptive statistics, $X^{2}$ test of independence in the contingency tables and logistic regression analysis were used.

Results: Regular alcohol consumption (at least weekly) was reported by $7.4 \%$ of children aged eleven, $19.3 \%$ of children aged thirteen and $38.4 \%$ of children aged fifteen years. Drunkenness at least twice in their life was admitted by $3 \%$ of children aged eleven, $15 \%$ of children aged thirteen and $43 \%$ of children aged fifteen years. Both alcohol consumption and drunkenness were significantly associated $(p<0.001)$ with age and gender. Formal structure of family was found to have significant effect on the experience of drunkenness, but no effect on alcohol consumption was recorded. Based on our results, neither the amount of time spent together, nor the children communication with parents had a statistically significant influence on alcohol consumption or drunkenness experience within each family type. However, statistically significant differences were observed between different family types $(p<0.001)$.

Conclusions: These findings indicate a high degree of liberalism of Czech society towards alcohol. It appears that alcohol consumption will remain a serious problem in Czech society, therefore, more attention should be paid to this phenomenon in the future.

Key words: HBSC study, alcohol consumption, family, Czech Republic, children

Address for correspondence: L. Hodačová, Charles University, Faculty of Medicine in Hradec Kralove, Department of Social Medicine, Šimkova 870, 50003 Hradec Kralove, Czech Republic. E-mail: hodacoval@lfhk.cuni.cz

https://doi.org/10.21101/cejph.a4381

\section{INTRODUCTION}

Alcohol is one of the most common risk factors for both morbidity and mortality worldwide. According to the World Health Organization (WHO) Report on Alcohol and Health, alcohol is responsible for $4 \%$ of the total annual mortality rate worldwide, the deaths are mostly due to accidents, cancer, cardiovascular disease, and liver disease (1). Alcohol increasingly negatively affects health of adolescents and young adults aged 15 to 29 years. In this age group it is causing $9 \%$ of deaths $(1,2)$.

Unfortunately, the Czech Republic is one of the countries with the highest consumption of alcohol in general and ranking first in beer consumption per capita. According to the CAGE screening scale, hazardous alcohol consumption concerns $17 \%$ of the population (which, converted to the adult population of the Czech Republic, represents 1.2 million people), harmful or problematic drinking concerns $8.2 \%$ of the population, i.e. 600,000 people (3).
Binge drinking, i.e. drinking five or more glasses of alcohol on one occasion, sometimes or often is reported by more than half of the adult population - over $60 \%$ of men and $40 \%$ women (4). Excessive alcohol consumption is a huge burden not only for individuals, but also for the whole society (2).

Risk behaviour of adults serves as a model for forming attitudes and behaviour of young people. Tolerance of adults towards alcohol causes teenagers' early acceptance of drinking as a common and normal part of social contacts and as an integral part of the celebrations and entertainments $(2,5,6)$. At the same time, alcohol in children and adolescents, besides other effects, affects negatively brain development, which influences the cognitive, emotional and social development of children (7). Drinking alcohol often occurs in the context of other risk behaviours such as smoking, drug use, risky sexual behaviour, truancy, bullying, negative attitude towards school, and aggressiveness, while in general the early onset strongly predicts later problems (8-10). 
In human life, family plays an important role, which may become the birthplace of a variety of developmental problems, including high-risk behaviour or, conversely, become a strong protective factor. Presence of both parents is ideal for child development. However, the quality of parenting rather than formal structure of a family in relation to the healthy development of children has been emphasized (11), where particularly marital conflict has a negative impact on the prosperity of children, their health and life satisfaction, both in marriage and after divorce (12).

For formation of a healthy lifestyle, completeness of the family, the level and quality of communication between children and parents, spending time together and respecting daily rituals, education and occupation of parents, their patterns of behaviour and parenting style are significant (13-20). In prevention of risk behaviour, checking teenagers by parents is recommended especially the establishment of clear rules and their compliance, consistency in upbringing, monitoring of adolescents, sanctions and rewards in relation to the behaviour of adolescents. Higher score of family management during adolescence reduces the incidence of problems in adulthood $(8,21)$. Although young people are becoming independent and family-orientation decreases in adolescence, the importance of parents as "referees" for the teenagers, however, remains $(8,22)$.

The aim of our work is to monitor and analyze the influence of chosen family indicators on alcohol consumption and experience of drunkenness in a representative sample of Czech children.

\section{MATERIALS AND METHODS}

Data for our work were obtained from the Health Behaviour in School Aged Children (HBSC) study - a World Health Organization (WHO) cross national study. This is a major international study that deals with monitoring the health and lifestyle of the maturing population of school children and, in a broad social context, tries to understand relationships that affect young people's health. Its methodology is based on WHO recommendations. The study has been ongoing in four-year intervals since 1983/1984, the Czech Republic has been participating since 1994 (15).

In our study, we used data from a representative sample of Czech children aged 11, 13 and 15 years. The sample consisted of 4,293 children; 2,066 boys (48.1\%) and 2,227 girls (51.9\%); $31.9 \%$ of children were aged $11(n=1,371)$, 33\% of children were aged $13(n=1,417)$ and $34.6 \%$ were aged $15(n=1,485)$. Twenty children $(0.5 \%)$ in total did not indicate their age but for further analysis these children were not excluded from the sample. From the original sample of HBSC study (4,425 children), the following groups of children were excluded from our analysis: children who, in the question relating to alcohol consumption, indicated never, rarely or every month only for one type of stated alcoholic beverages and failed to provide any response for other types of beverages (58 children); children living in children's homes (10 children), children who answered ambiguously the question about the main home (4 children); and children who did not understand the question concerning communication with their parents (60 children).

Data collection was conducted in accordance with the criteria set by the International Coordination Council of the project. It was implemented in June 2010 in 88 randomly selected primary and high schools after obtaining the consent of the school directors. Students filled in questionnaires during one lesson in the presence of trained persons capable to provide the children with any additional explanation. Parents of the children were informed about the research in advance in writing. The condition for the inclusion of pupils into the study was the absence of negative statement of the parents. None of the surveyed pupils refused to participate in the research (23).

The questionnaire included 75 items and covered several thematically distinct domains: basic socio-demographic data, eating habits, physical activity, leisure activities, addictive behaviour, family, psychosocial adaptation, psychosomatic problems, perception of health, life satisfaction, accidents, school, and socioeconomic situation. In our work, we focused on the analysis of alcohol consumption and children's experience of drunkenness in relation to the formal structure of the family, the amount of time spent together with family and the quality of communication with parents.

We defined the formal structure of the family from the part in which children responded to the question with whom they live at their so-called main home. There were seven responses of choice (biological mother, biological father, stepmother, stepfather, grandmother, grandfather, children's home) and one more option for adding their own answer in case when none of the seven offered options fitted.

For the analysis, we divided the family, in terms of its formal structure, into four categories:

- In category A were children who reported that they live with both biological parents;

- In category B were children who reported that they live with one biological and one step-parent;

- In category $\mathrm{C}$ were children who reported that they live with only one biological parent;

- In category D were children who reported that they do not live with their parents.

We assessed the amount of time spent together on the basis of responses to the question which identified various ways in which the family spends their leisure time. For the analysis, two items were selected which we believe a family should do every day or almost every day: "We are together when eating; we sit together and talk about different things.” Children could respond using a five-point scale with the following options: every day, almost every day, once a week, less often, and never. According to the amount of time spent together, we divided the children into two groups. If children stated that they do spend time with their family every day or almost every day, and the average of their answers ranged from 1 to 2.4, we included them in the group in which members of the family spend a lot of time together. When the mean of answers reached values of 2.5 and more, we included the children in the group of families who spend little time together.

We assessed the quality of communication with parents on the basis of the question: "How easy is it for you to talk with your mother/father about the things that are really bothering you?” The children could respond in case of each parent using a five-point scale: very easy, easy, difficult, very difficult, I do not have such person. If the children replied that it was very easy or easy to talk to both parents, they were included in the category very good communication. If they answered that it was very easy or easy to talk to at least one parent, they were included in the category good 
communication. If they answered that they find talking to parents difficult or very difficult, they were included in the category poor communication. Children could give an answer - I do not have such person. A total of 22 children stated that they have neither mother nor father.

Alcohol consumption was assessed using the question: "How often have you currently been drinking alcoholic beverages such as beer, wine or spirits? (Include in your reply also the cases or situations when you drink even only very small amounts of these drinks)." Response options were: daily, every week, each month, rarely (less than once a month), never.

Children were divided into 3 categories:

- In category A I were children who did not drink alcohol at all or stated that they drink infrequently (less than once a month);

- In category A II were children who stated that they drink alcohol every month;

- In category A III were children who stated that they drink alcohol every day or every week.

Another important factor was the children's experience of drunkenness. Repeated alcohol consumption leading to drunkenness among adolescents refers to the acquisition of practices of dangerous binge drinking. The assessment of drunkenness was based on answers to the question: "Have you ever drunk such a quantity of alcohol that you were really drunk?” Children chose from the following answers: no, never; yes, once; yes, 2-3 times; yes, 4-10 times; yes, more than 10 times. Experience with drunkenness was divided into three categories: category 1 - children replied that they were never drunk; category 2 - yes, once; category 3 - children reported repeated experience with intoxication (drunkenness has occurred at least twice).

First, we analyzed alcohol consumption and drunkenness for the entire sample of children, and then in terms of age and gender. We carried out the further analysis of the formal family structure, the amount of time spent together and quality of communication with parents only in 15-year old children, as the experience of these children in relation to risk behaviour is much more common than in children of eleven and thirteen years of age.

Statistical data analysis was performed in the program NCSS 9 , methods of descriptive statistics and $\chi^{2}$ test of independence in the contingency tables were used. To assess the influence of the family on the monitored indicators, logistic regression analysis was used, and OR (odds ratio) was calculated with 95\% confidence interval (95\% CI).

\section{RESULTS}

Regular alcohol consumption (at least weekly) was reported by $7.4 \%$ of children aged eleven, $19.3 \%$ of children aged thirteen and $38.4 \%$ of children aged fifteen. Differences between age groups were statistically significant at $\mathrm{p}<0.001$. The risk of regular consumption of alcohol is 11 times greater in children aged 15 years in comparison with children aged 11 years $(\mathrm{OR}=11.42$, 95\% CI 9.05-14.42, $\mathrm{p}<0.001)$. In terms of gender, significantly more boys than girls stated that they consumed alcohol at least once a week $(\mathrm{OR}=1.50,95 \%$ CI $1.29-1.74, \mathrm{p}<0.001)$.

Subsequently, we analyzed the children's experience of drunkenness. Almost $90 \%$ of children aged eleven, $67 \%$ of children aged thirteen and less than $40 \%$ of children aged fifteen said they do not have any experience with drunkenness. Drunkenness at least twice in their life was admitted by $3 \%$ of children aged eleven, $15 \%$ of children aged thirteen and $43 \%$ of children aged fifteen. Differences between age groups were statistically significant at $\mathrm{p}<0.001$. The risk of repeated drunkenness increases with age, in 15-year old children it was 26 times greater than in 11-year olds $(\mathrm{OR}=25.92,95 \%$ CI 18.5-36.3, $\mathrm{p}<0.001)$, while 11-year olds are significantly more likely to have no experience with drunkenness $(11 / 15$ years OR $=14.11,95 \%$ CI $11.53-17.27, \mathrm{p}<0.001)$. In terms of gender, no experience with drunkenness was reported by almost two thirds of both girls and boys. Significantly more boys than girls reported experience with drunkenness at least twice $(\mathrm{OR}=1.29,95 \%$ CI $1.11-1.49, \mathrm{p}<0.001)$. The results are shown in Table 1.

Further analysis of the risk behaviour with respect to the family was carried out only in children aged 15 . Frequent alcohol consumption (at least weekly) was reported by nearly $40 \%$ of children regardless of the time spent with family and category of the family (except for D category family). No statistically significant effect of family or the amount of time spent together on alcohol consumption was recorded. In terms of experience with drunkenness, no experience was indicated mostly by children living in complete families (41.5\%), significant difference was observed

Table 1. Alcohol consumption and drunkenness (\%)

\begin{tabular}{|c|c|c|c|c|c|c|}
\hline & \multirow{2}{*}{$\begin{array}{l}\text { Whole group } \\
n=4,293\end{array}$} & \multicolumn{3}{|c|}{ Age } & \multicolumn{2}{|c|}{ Gender } \\
\hline & & $\begin{array}{l}11 \text { y-old } \\
n=1,371\end{array}$ & $\begin{array}{l}13 \text { y-old } \\
n=1,417\end{array}$ & $\begin{array}{l}15 y \text {-old } \\
n=1,485\end{array}$ & $\begin{array}{c}\text { Boys } \\
n=2,066\end{array}$ & $\begin{array}{c}\text { Girls } \\
n=2,227\end{array}$ \\
\hline \multicolumn{7}{|l|}{ Alcohol } \\
\hline $\mathrm{Al}$ & 61.5 & 85.3 & 62.5 & 38.5 & 58 & 64.5 \\
\hline All & 16.4 & 7.3 & 18.3 & 23.1 & 16.5 & 16.4 \\
\hline Alll & 22.1 & 7.4 & 19.3 & 38.4 & 25.5 & 22.1 \\
\hline \multicolumn{7}{|l|}{ Drunkenness } \\
\hline No, never & 64.0 & 89.4 & 67.3 & 37.5 & 62.6 & 65.3 \\
\hline Yes, once & 15.2 & 7.8 & 17.3 & 19.9 & 14.4 & 15.9 \\
\hline At least $2 \mathrm{x}$ & 20.8 & 2.8 & 15.4 & 42.6 & 23 & 18.8 \\
\hline
\end{tabular}

A I - children who did not drink alcohol at all, or stated that they drink infrequently (less than once a month); A II - children who stated that they drink alcohol every month; A III - children who stated that they drink alcohol every day or every week. 
compared to families $\mathrm{B}$ and $\mathrm{C}(\mathrm{OR}=1.98,95 \% \mathrm{CI} 1.44-2.72$, $\mathrm{p}<0.001$ and $\mathrm{OR}=1.5,95 \%$ CI 1.12-2.01, $\mathrm{p}<0.01)$. Children from complete families had also significantly lower experience with frequent drunkenness than children from families B and C $(p<0.001)$. The amount of time spent together had no statistically significant effect on the experience of drunkenness. The results are shown in Table 2.

The influence of time spent together in individual families on alcohol and drunkenness is shown in Table 3. On the basis of our results, we can conclude that there were no statistically significant differences between the amount of time spent together and alcohol consumption or drunkenness experience in children within each family category, where the data for $\mathrm{D}$ families is only informative due to small numbers of respondents. However, statistically significant differences were observed between particular families. Children from families A, B and C, who spent a little time with their family, had 1.3-2.5 times higher risk of repeated drunkenness compared with children from families $\mathrm{A}$, who spent a lot of time with their family: A little time/A lot of time (OR $=1.31,95 \% \mathrm{CI}$ $1.00-1.72, \mathrm{p}<0.05)$; B little time/A lot of time $(\mathrm{OR}=2.08,95 \%$ CI $1.4-3.09, \mathrm{p}<0.001)$; C little time/A lot of time $(\mathrm{OR}=2.46$, 95\% CI 1.66-3.64, $\mathrm{p}<0.001)$.
Subsequently, we analyzed risk factors observed in the context of children's communication with parents. However, we did not include the results of $\mathrm{D}$ families into the analysis due to small number of respondents ( 25 children), which, after further division in terms of categories of alcohol consumption (experience with drunkenness) and type of communication in some subgroups, left only a few individuals, sometimes only one or none. The results would therefore be distorted.

The influence of communication quality on the experience of alcohol consumption and drunkenness in 15-year old children is shown in Table 4. The differences in alcohol consumption in 15 -year old children within different family categories do exist but statistically significant effect $(p<0.05)$ was observed only in communication within the families B (significantly more children with poor communication reported that they do not drink alcohol and significantly more children with very good communication reported hazardous alcohol drinking). The influence of communication on the experience of drunkenness within individual categories of families in our group was not proved. Nevertheless, statistically significant differences related to the quality of communication and formal structure of the family were observed between different categories of families $(p<0.001)$.

Table 2. Alcohol consumption and drunkenness depending on formal structure of a family and the amount of time spent together (\%)

\begin{tabular}{|c|c|c|c|c|c|c|}
\hline & \multicolumn{4}{|c|}{ Formal structure of a family } & \multicolumn{2}{|c|}{ Time spent together } \\
\hline & $\begin{array}{c}A \\
n=983\end{array}$ & $\begin{array}{c}B \\
n=224\end{array}$ & $\begin{array}{c}c \\
n=253\end{array}$ & $\begin{array}{c}D \\
n=25\end{array}$ & $\begin{array}{c}\text { A lot of time } \\
n=578\end{array}$ & $\begin{array}{c}\text { Little time } \\
n=880\end{array}$ \\
\hline \multicolumn{7}{|l|}{ Alcohol } \\
\hline Al & 39.2 & 34.4 & 39.5 & 40.0 & 39.6 & 38.1 \\
\hline All & 22.0 & 27.6 & 24.9 & 8.0 & 22.7 & 23.5 \\
\hline A III & 38.8 & 38.0 & 35.6 & 52 & 37.7 & 38.4 \\
\hline \multicolumn{7}{|l|}{ Drunkenness } \\
\hline No, never & 41.5 & 26.4 & 32.2 & 34.6 & 39.9 & 36.5 \\
\hline Yes, once & 20.1 & 20.3 & 17.6 & 30.8 & 21.3 & 19.0 \\
\hline At least $2 \mathrm{x}$ & 38.4 & 53.3 & 50.2 & 34.6 & 38.8 & 44.5 \\
\hline
\end{tabular}

Formal structure of family: A - children who reported that they live with both biological parents; B - children who reported that they live with one biological and one stepparent; C - children who reported that they live with only one biological parent; D - children who reported that they do not live with their parents.

Table 3. Alcohol consumption and drunkenness depending on the amount of time spent together in different categories of families (\%)

\begin{tabular}{|c|c|c|c|c|c|c|c|c|}
\hline & \multicolumn{2}{|c|}{ A } & \multicolumn{2}{|c|}{ B } & \multicolumn{2}{|c|}{ C } & \multicolumn{2}{|c|}{ D } \\
\hline & $\begin{array}{c}\text { A lot of time } \\
n=378\end{array}$ & $\begin{array}{l}\text { Little time } \\
n=586\end{array}$ & $\begin{array}{l}\text { A lot of time } \\
n=85\end{array}$ & $\begin{array}{c}\text { Little time } \\
n=138\end{array}$ & $\begin{array}{c}\text { A lot of time } \\
n=104\end{array}$ & $\begin{array}{c}\text { Little time } \\
n=142\end{array}$ & $\begin{array}{c}\text { A lot of time } \\
n=11\end{array}$ & $\begin{array}{c}\text { Little time } \\
n=14\end{array}$ \\
\hline \multicolumn{9}{|l|}{ Alcohol } \\
\hline $\mathrm{Al}$ & 39.2 & 39.6 & 36.5 & 32.6 & 43.3 & 37.3 & 45.5 & 35.7 \\
\hline All & 22.7 & 21.7 & 23.5 & 30.4 & 23.1 & 26.1 & 9.1 & 7.2 \\
\hline A III & 38.1 & 38.7 & 40.0 & 40.0 & 33.6 & 36.6 & 45.4 & 57.1 \\
\hline \multicolumn{9}{|l|}{ Drunkenness } \\
\hline No, never & 43.0 & 41.3 & 27.6 & 25.2 & 39.0 & 28.0 & 36.4 & 35.7 \\
\hline Yes, once & 23.0 & 18.3 & 16.1 & 23.0 & 19.1 & 16.1 & 27.2 & 35.7 \\
\hline At least $2 \mathrm{x}$ & 34.0 & 40.4 & 56.3 & 51.8 & 41.9 & 55.9 & 36.4 & 28.6 \\
\hline
\end{tabular}

A, B, C, D-categories of families 
Table 4. Alcohol consumption and drunkenness depending on the quality of communication with parents (\%)

\begin{tabular}{|c|c|c|c|c|c|c|c|c|c|}
\hline & \multicolumn{3}{|c|}{$A$} & \multicolumn{3}{|c|}{ B } & \multicolumn{3}{|c|}{ C } \\
\hline & \multicolumn{9}{|c|}{ Communication with parents } \\
\hline & $\begin{array}{c}\text { Very good } \\
n=484\end{array}$ & $\begin{array}{c}\text { Good } \\
n=311\end{array}$ & $\begin{array}{c}\text { Bad } \\
n=180\end{array}$ & $\begin{array}{c}\text { Very good } \\
n=74\end{array}$ & $\begin{array}{c}\text { Good } \\
n=121\end{array}$ & $\begin{array}{c}\text { Bad } \\
n=28\end{array}$ & $\begin{array}{c}\text { Very good } \\
n=78\end{array}$ & $\begin{array}{c}\text { Good } \\
n=123\end{array}$ & $\begin{array}{c}\text { Bad } \\
n=48\end{array}$ \\
\hline \multicolumn{10}{|l|}{ Alcohol } \\
\hline Al & 44.4 & 37.4 & 36.1 & 29.7 & 33.1 & 50.0 & 35.9 & 40.7 & 41.7 \\
\hline All & 21.8 & 20.7 & 24.5 & 20.3 & 33.1 & 25.0 & 23.1 & 25.2 & 27.1 \\
\hline A III & 33.8 & 41.9 & 39.4 & 50.0 & 33.9 & 25.0 & 41.0 & 34.2 & 31.3 \\
\hline \multicolumn{10}{|l|}{ Drunkenness } \\
\hline No, never & 43.9 & 42.2 & 36.5 & 22.7 & 27.6 & 28.6 & 30.8 & 34.7 & 26.5 \\
\hline Yes, once & 20.2 & 20.0 & 18.6 & 21.3 & 19.5 & 21.4 & 15.4 & 14.5 & 30.6 \\
\hline At least $2 \mathrm{x}$ & 35.9 & 37.8 & 44.9 & 56.0 & 52.9 & 50.0 & 53.8 & 50.8 & 42.9 \\
\hline
\end{tabular}

A, B, C - categories of families

\section{DISCUSSION}

In our work, we focused on monitoring and analysis of alcohol consumption in a representative sample of Czech children aged 11, 13 and 15 years. In 15-year old children, the analysis of risk behaviour associated with selected family indicators was subsequently conducted. Alcohol consumption was significantly related to the age and gender of children. The proportion of children who reported regular alcohol consumption increased with age. The finding that in the category of 15-year old children nearly $40 \%$ of them reported regular alcohol consumption is rather serious. In terms of gender, regular alcohol consumption was reported more frequently by boys. Gender differences in terms of risk behaviour (to the detriment of boys) are also shown in the HBSC study results from other countries $(13,15)$.

Comparison of regular alcohol consumption (at least weekly) within the countries participating in the HBSC study turns out unfavourable for the Czech Republic. Czech children in all three age categories exceeded in this area the average values achieved in the HBSC study and in terms of prevalence of regular alcohol consumption, they were ranked first in the category of 13 and 15 year olds, and 11 years old children then were ranked fourth among all monitored countries (15).

Long-term results of the HBSC study in the Czech Republic show significant increase in prevalence of drinking in school-age children. Czech children are characterized by a low rate of abstinence observed consistently in all measurements. Most children already had experience with alcohol even in the lowest age group of 11 years, thereby Czech children differ from the vast majority of other countries $(15,23)$. These findings indicate a high degree of liberalism of Czech society towards alcohol.

Spread of alcohol consumption among young people is also confirmed by the results of the ESPAD study from 2011. The vast majority (98\%) of 16-year olds reported that they consume alcoholic beverages and about $60 \%$ of 16 -year olds can be considered regular drinkers. Binge drinking of large doses of alcohol has also been spreading among young people. The fact that the risk of alcohol consumption and smoking in relation to health has been significantly underestimated by a large part of young people is alarming $(2,4)$.
In addition, children and adolescents represent, in terms of risk behaviour, particularly vulnerable group often unable to consider the long-term impact of the risks of smoking and alcohol consumption. They are much more influenced by the patterns in their surroundings $(8,9)$. In addition, hazardous alcohol consumption is often associated with other health damaging behaviours, such as smoking, drug use, risky sexual behaviour, and also with increased aggression, bullying, and truancy $(6,24)$.

As presumed, the experience with drunkenness of children in our sample increased with age. Boys reported significantly more frequent experience with repeated drunkenness than girls. In comparison with other countries that participated in the HBSC study, with regard to repeated drunkenness, Czech children were again placed in all age categories above average, i.e. among the first ten (15). Repeated alcohol consumption leading to drunkenness among adolescents may result in the practice of dangerous binge drinking.

Another analysis of risk behaviour associated with alcohol consumption was conducted in the group of 15-year olds. Risk behaviour increases with age, the breaking point in behaviour occurs most often between the ages of 13 and 15 (9, 15, 22), i.e. in 11 and 13-year old children the risk behaviour is much less frequent than in children aged 15 years. We were interested in what is the influence of a family on the risk of alcohol consumption.

Based on our results, no statistically significant effect of formal family structure on alcohol consumption was proved. About $40 \%$ of children reported regular alcohol consumption in all categories of families. This conclusion contradicts the results of other studies. Researches generally agree that adolescents from single-parent and reconstituted families are at significantly greater risk of alcohol use than adolescents from intact families $(8,25,26)$. On the other hand, statistically significant effect of the formal family structure in relation to the experience of children with drunkenness was registered in our study. No experience with drunkenness was reported most frequently by children from intact families. Also, children from intact families the least frequently reported experience with repeated drunkenness.

The statistically significant influence of communication quality on the risk of alcohol consumption and drunkenness as well as the effect of the amount of time spent together with the family 
on children's alcohol consumption or drunkenness in the 15year olds in different family categories were not demonstrated in our work.

This could be explained by the increasing importance and influence of peers in this age group. As young people grow older, the influence of parents as well as the degree of parental control decreases. The protective effect of parents (secure emotional bonds, parental control, monitoring, family cohesion, communication, management skills, and attitudes) on adolescent alcohol use may be modified by the peer influence $(8,11,27,28)$. Especially having substance-using and deviant peers has been recognized as an important predictor of adolescent substance use (29, 30).

Alcohol use among children is strongly affected by a number of additional factors, such as the child personality characteristics (i.e. disinhibition, novelty seeking, delinquency), genetic predispositions, sociocultural background, parenting style, school environment, the socioeconomic status and education of parents, and parental alcohol use $(8,9,24,30)$. Children of this age group tend to experiment and try "forbidden fruit", socioeconomic inequalities in behavior also negatively affect health in adolescence (10, 31). High tolerance of Czech society towards alcohol drinking may play an important role as well.

However, it should be pointed out that the results of our investigation are entirely dependent on children's subjective responses and cannot be objectively verified. Another limitation of our study is that for family influence analysis we evaluated only a few indicators and we did not chart family data comprehensively. We proceeded from the options given by the questionnaire; thus family factors such as parenting style, emotional bonds, parental control, monitoring, family cohesion, management skills and attitudes, attitudes to adolescent drinking as well as parental substance use, that are known to influence adolescent drinking and the onset of substance use, were not analyzed.

\section{CONCLUSSIONS}

Evaluation of health and risk behaviour of young generation in the broad social context is one of the important fields of research.

Based on current knowledge, it appears that in Czech society alcohol will remain a serious problem in the future. Prevention of alcohol related problems is underestimated in the Czech Republic. In the society, there is a widespread belief that the greatest threat of disintegration are illegal drugs, while alcohol problems are related to the failure of individuals. The result is significant damages caused by alcohol $(2,4)$. Intervention at puberty onset should be directed to the prevention of alcohol consumption and then, at higher age, to the prevention of consumption of larger doses $(14,24)$.

\section{Acknowledgements}

The study was supported by the programme PRVOUK P37/09 and PROGRES Q40-09, and by the Czech Ministry of Education, Youth and Sports (MEYS) under Contracts No. LG14042 and No. LG 14043.

\section{Conflict of Interests}

None declared

\section{REFERENCES}

1. World Health Organization. Global status report on alcohol and health 2014 [Internet]. Geneva: WHO; 2014 [cited 2014 Aug 2]. Available from: http://apps.who.int/iris/bitstream/10665/112736/1/9789240692763_eng. pdf?ua=1.

2. Csémy L, Sovinová H, Procházka B. Alcohol consumption and marijuana use in young adult Czechs. Cent Eur J Public Health. 2012 Dec;20(4):2447.

3. Mravčík V, Chomynová P, Grohmannová K, Nečas V, Grolmusová L, Kiššová L, et al. Annual report: the Czech Republic - 2012 drug situation. Prague: Office of the Government of the Czech Republic; 2013.

4. Chomynová P. National research on substance abuse 2012: smoking, alcohol consumption and other drugs in general population. Focused on drugs [Internet]. 2013 Apr [cited 2014 Mar 27];11(2):1-12. Available from: http:/www.drogy-info.cz/publikace/zaostreno-na-drogy/2013zaostreno-na-drogy/02-13-narodni-vyzkum-uzivani-navykovych-latek/. (In Czech.)

5. McMorris BJ, Catalano RF, Kim MJ, Toumbourou JW, Hemphill SA. Influence of family factors and supervised alcohol use on adolescent alcohol use and harms: similarities between youth in different alcohol policy contexts. J Stud Alcohol Drugs. 2011 May;72(3):418-28.

6. Ryan SM, Jorm AF, Lubman DI. Parenting factors associated with reduced adolescent alcohol use: a systematic review of longitudinal studies. Aust N Z J Psychiatry. 2010 Sep;44(9):774-83.

7. Crews F, He J, Hodge C. Adolescent cortical development: a critical period of vulnerability for addiction. Pharmacol Biochem Behav. 2007 Feb;86(2):189-99.

8. Čablová L, Pazderková K, Miovský M. Parenting styles and alcohol use among children and adolescents: a systematic review. Drugs: Education, Prevention and Policy. 2014; 21(1):1-13.

9. Wang RH, Hsu HY, Lin SY, Cheng CP, Lee SL. Risk behaviours among early adolescents: risk and protective factors. J Adv Nurs. 2010 Feb;66(2):313-23.

10. Jackson CA, Henderson M, Frank JW, Haw SJ. An overview of prevention of multiple risk behaviour in adolescence and young adulthood. J Public Health (Oxf). 2012 Mar;34 Suppl 1:i31-40. doi: 10.1093/pubmed/fdr113.

11. Bergh D, Hagquist C, Starrin B. Parental monitoring, peer activities and alcohol use: a study based on data on Swedish adolescents. Drugs: Education, Prevention and Policy. 2011;18(2):100-7.

12. Pavlát J. Children in aftermath of divorce - summary of english written and our literature. Cesk Psychol. 2012;56(3):221-31. (In Czech.)

13. Currie C, Gabhainn SN, Godeau E, Roberts C, Smith R, Currie D, et al. Inequalities in young people's health: health behaviour in school-aged children international report from the 2005/2006 survey. Copenhagen: WHO Regional Office for Europe; 2008.

14. Jackson C, Geddes R, Haw S, Frank J. Interventions to prevent substance use and risky sexual behaviour in young people: a systematic review. Addiction. 2012 Apr;107(4):733-47.

15. Currie C, Zanotti C, Morgan A, Currie C, Looze M, Roberts C, et al. Social determinants of health and well-being among young people: health behaviour in school-aged children (HBSC) study: international report from the 2009/2010 survey. Copenhagen: WHO Regional Office for Europe; 2012.

16. Levin KA, Kirby J, Currie C. Adolescent risk behaviours and mealtime routines: does family meal frequency alter the association between family structure and risk behaviour? Health Educ Res. 2012 Feb;27(1):2435.

17. Phillips TM. The Influence of family structure vs. family climate on adolescent well-being. Child and Adolescent Social Work Journal. 2012;29(2):103-10.

18. Herrenkohl TI, Lee JO, Kosterman R, Hawkins JD. Family influences related to adult substance use and mental health problems: a developmental analysis of child and adolescent predictors. J Adolesc Health. 2012 Aug;51(2):129-35.

19. Fan Y, Chen Q. Family functioning as a mediator between neighborhood conditions and children's health: evidence from a national survey in the United States. Soc Sci Med. 2012 Jun;74(12):1939-47.

20. Elgar FJ, Craig W, Trites SJ. Family dinners, communication, and mental health in Canadian adolescents. J Adolesc Health. 2013 Apr;52(4):433-8.

21. Bakker MP, Ormel J, Verhulst FC, Oldehinkel AJ. Adolescent family adversity and mental health problems: the role of adaptive self-regulation capacities. The TRAILS study. J Abnorm Child Psychol. 2011 Apr;39(3):341-50. 
22. Armstrong JM, Ruttle PL, Burk LR, Costanzo PR, Strauman TJ, Essex MJ. Early risk factors for alcohol use across high school and its covariation with deviant friends. J Stud Alcohol Drugs. 2013 Sep;74(5):746-56.

23. Kalman M, Sigmund E, Sigmundová D, Hamřík Z, Beneš L, Benešová D, et al. National report on health and lifestyle in school-aged children: based on the international research implemented in 2010 within international study „Health Behaviour in School-aged Children: WHO collaborative cross-national study (HBSC)“. Olomouc: Palacký University Olomouc; 2011. (In Czech.)

24. Berge J, Sundell K, Öjehagen A, Håkansson A. Role of parenting styles in adolescent substance use: results from a Swedish longitudinal cohort study. BMJ Open. 2016 Jan 14;6(1):e008979. doi: 10.1136/bmjopen-2015-008979.

25. Fröjd S, Kaltiala-Heino R, Rimpelä M. The association of parental monitoring and family structure with diverse maladjustment outcomes in middle adolescent boys and girls. Nord J Psychiatry. 2007;61(4):296-303.

26. Parvizy S, Ahmadi F. A qualitative study on adolescence, health and family. Ment Health Fam Med. 2009 Sep;6(3):163-72.

27. Latendresse SJ, Rose RJ, Viken RJ, Pulkkinen L, Kaprio J, Dick DM. Parental socialization and adolescents' alcohol use behaviors: predictive disparities in parents' versus adolescents' perceptions of the parenting environment. J Clin Child Adolesc Psychol. 2009 Mar;38(2):232-44.

28. Feinberg ME, Jones DE, Cleveland MJ, Greenberg MT. The community epidemiology of underage drinking: variation across communities in relations of risk to alcohol use. Prev Sci. 2012 Dec;13(6):551-61.

29. Marschall-Lévesque S, Castellanos-Ryan N, Vitaro F, Séguin JR. Moderators of the association between peer and target adolescent substance use. Addict Behav. 2014 Jan;39(1):48-70.

30. Monahan KC, Rhew IC, Hawkins JD, Brown EC. Adolescent pathways to co-occurring problem behavior: the effects of peer delinquency and peer substance use. J Res Adolesc. 2014 Dec 1;24(4):630-645.

31. van Lenthe FJ, de Bourdeaudhuij I, Klepp KI, Lien N, Moore L, Faggiano F, et al. Preventing socioeconomic inequalities in health behaviour in adolescents in Europe: background, design and methods of project TEENAGE. BMC Public Health. 2009 May 8;9:125. doi: 10.1186/14712458-9-125.

Received April 4, 2015 Accepted in revised form February 8, 2016 